\title{
Análise do conforto térmico em galpões avícolas com diferentes sistemas de acondicionamento
}

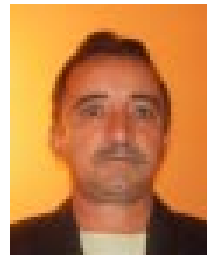

Dermeval A. Furtado ${ }^{1}$, Pedro V. de Azevedo ${ }^{2}$ \& Ilda de F. F. Tinôco ${ }^{3}$

1 DEAg/CCT/UFCG. Fone: (83) 310-1486. E-mail: dermeval@deag.ufcg.edu.br (Foto)

2 DCA /CCT/UFCG. Fone: (83) 310-1189. E-mail: pvieira@dca.ufcg.edu.br

3 DEA/UFV. Fone: (31) 3899-1884. E-mail: iftinoco@mail.ufv.br

Protocolo $84-7 / 5 / 2003$ - Aprovado em 31/10/2003

\begin{abstract}
Resumo: A base deste trabalho foi a análise da influência da tipologia e das condições de conforto térmico ambiental em sete sistemas de acondicionamento de aviários de frangos de corte, localizados na mesorregião do Agreste paraibano. Os sistemas foram os seguintes: telha de amianto sem ventilação artificial; telha de barro sem ventilação artificial; telha de amianto com ventilação artificial; telha de barro com ventilação artificial; telha de amianto com ventilação artificial e nebulização; telha de barro com ventilação artificial e nebulização e telha de amianto com ventilação artificial e aspersão sobre a cobertura. A avaliação foi feita com base na temperatura do ar (TA), na umidade relativa (UR), no índice de temperatura de globo negro e umidade (ITGU) e na carga térmica de radiação (CTR) em diferentes horários, durante o período de verão. Constatouse influência da tipologia nas condições de conforto térmico e que em todos os sistemas os índices de conforto variaram ao longo do dia, sendo que a TA, o ITGU e a CTR, apresentaram valores considerados acima do ideal, enquanto a UR ficou dentro da zona de conforto térmico.
\end{abstract}

Palavras-chave: tipos de cobertura, ambiência, conforto térmico, avicultura

\section{Thermal comfort analysis in poultry houses with different acclimatization systems}

\begin{abstract}
The study had the objective of analyzing the influence of seven types of roofs on thermal comfort in poultry-house, in the region of "Paraíba Agreste'. The systems were: asbestos tiles and clay tiles without forced ventilation, asbestos tiles and clay tiles with forced ventilation, asbestos tiles and clay tiles with artificial ventilation and fogging and asbestos tiles with forced ventilation, fogging and sprinkling on the roof. The evaluation was based on the results of air temperature (AT), relative humidity $(\mathrm{RH})$, black globe temperature (BGT) and the radiation thermal charge (RTC), measured at different diurnal times during the summer. Influence of the roof types on the thermal comfort was observed. In all systems the comfort index evaluated varied during the day and that AT, BGT and RTC showed values higher than those considered optimum. The $\mathrm{RH}$ values were within the thermal comfort zone.
\end{abstract}

Key words: roof type, thermal comfort, poultry

\section{INTRODUÇÃO}

A avicultura mundial apresentou, no ano 2002, uma produção de 46.097 milhões de toneladas, sendo que no Brasil ela foi de 7,2 milhões de toneladas de carne de frango (ABEF, 2003), o que mantém o País como segundo maior produtor mundial, em que as exportações de carne de frango trouxeram divisas de mais de um bilhão de dólares e, atualmente, mais de 60 países compram nosso produto. O consumo interno per capita de carne de frango alcançou $29,4 \mathrm{~kg} \mathrm{ano}^{-1}$, colocando os brasileiros entre os grandes consumidores mundiais dessa carne.

Para o aprimoramento da produção avícola intensiva em países tropicais como o Brasil, precisa-se aperfeiçoar os abrigos e equacionar o manejo para superar os efeitos prejudiciais provenientes de alguns fatores ambientais críticos. No País, nota-se aumento da criação de aves confinadas, as quais exigem abrigos específicos para fazer frente a determinadas condições ambientais e, certamente, irão refletir na produtividade do sistema (Moura, 2001).

Em climas tropicais e subtropicais, a exemplo do Brasil, os elevados valores de temperatura e umidade relativa do ar encontram-se entre os principais fatores que interferem negativamente nesta atividade (Tinôco, 1998). Dentre os fatores do ambiente, os térmicos são os que afetam mais diretamente a ave, pois comprometem sua função vital mais importante, que é a manutenção de sua homeotermia (Baêta \& Souza, 1997). Se essas condições estão próximas das ideais, é grande a probabilidade de se obter alta produtividade. 
A zona de termoneutralidade está relacionada a um ambiente térmico ideal, onde as aves encontram condições perfeitas para expressar suas melhores características produtivas. Baêta \& Souza (1997) e Tinôco (2001) consideram o ambiente confortável com temperaturas entre 18 e $28^{\circ} \mathrm{C}$ e umidade relativa entre $50 \mathrm{e}$ $70 \%$. Teixeira (1983) pesquisando instalações para frangos de corte na região de Viçosa e Visconde do Rio Branco, MG, concluiu que da terceira à sexta semana, os ambientes cujos valores de índice de temperatura do globo negro e umidade (ITGU) variaram entre 65,0 e 77,0, não afetaram o desempenho dos frangos e, portanto, foram considerados confortáveis para produção; na última semana, os ambientes com valores de ITGU variando entre 73,3 e 80,5 foram considerados desconfortáveis em virtude das condições térmicas desfavoráveis. Em trabalho realizado por Rosa (1984) foram obtidos, às 14 h, em um dia típico de céu claro com 12,3 h de insolação, em Viçosa, MG, valores de carga térmica de radiação (CTR) de 515,4 $\mathrm{W} \mathrm{m}^{-2}$ para galpões com telhas de cimento amianto e 498,3 $\mathrm{W} \mathrm{m}^{-2}$ para telhas de barro (francesa).

Do ponto de vista bioclimático, um dos principais fatores que influenciam na carga térmica de radiação incidente são os telhados, principalmente em decorrência dos materiais de cobertura (Silva \& Sevegnani, 2001). Para Nããs et al. (2001) o telhado é o elemento construtivo mais significativo em uma instalação avícola, quanto ao controle da radiação solar incidente. Rosa (1984) concluiu que o fluxo de calor através das coberturas, juntamente com as elevadas temperaturas na face inferior das telhas, é a causa principal do desconforto no interior das instalações.

A ventilação é necessária para eliminar o excesso de umidade do ambiente e da cama, provenientes da água liberada pela respiração das aves e dos dejetos, permitir a renovação do ar e eliminar odores (Tinôco,1998), e que uma das alternativas para melhorar as condições térmicas e promover a renovação do ar, é a ventilação forçada. Quando não há problemas com a saturação do ar dentro dos aviários, pode-se utilizar o sistema de resfriamento evaporativo, constituído basicamente pelo uso de nebulizadores, permitindo que o ar não saturado do ambiente entre em contato com a água em temperatura mais baixa, ocorrendo então a troca de calor entre o ar e a água. Para reduzir a temperatura da telha e circunvizinhança nas horas de calor intenso, pode-se utilizar aspersão sobre a cobertura.

As pesquisas realizadas no Brasil sobre conforto térmico para aviários foram, na maioria, realizadas nas regiões Sul e Sudeste, havendo poucas informações sobre essas condições na região Nordeste. Ante o exposto, este trabalho teve como objetivo analisar sete sistemas de acondicionamento térmico ambiental de aviários para frangos de corte, em condições de verão.

\section{MATERIAL E MÉTODOS}

Este trabalho foi realizado nas granjas de frangos de corte localizadas na Mesorregião do Agreste do Estado da Paraíba, que representa $23,11 \%$ do Estado e é responsável por aproximadamente $50 \%$ da produção avícola paraibana, realizado no período de setembro de 2001 a março de 2002, quando ocorre a estação seca e são registradas as maiores temperaturas. As granjas utilizadas pertenciam à empresa GUARAVES -
Guarabira Aves S.A. e as granjas integradas à empresa agrícola "Santíssimo", localizadas nas microrregiões de Campina Grande (coordenadas geográficas: 7¹5'18" S, 3552'28" O e altitude média de $550 \mathrm{~m}$ ) e Guarabira (coordenadas geográficas $6^{0} 51$ ' 18 " S; 35 29' 24" O e altitude média de 98 m). O clima da região, de acordo com a classificação de Koppen adaptada ao Brasil (Brasil, 1972) é do tipo climático As', quente e úmido.

Estudou-se a influência da tipologia dos galpões e de sete diferentes sistemas de acondicionamento, baseados principalmente no tipo de material de cobertura por ser este um dos principais fatores que influenciam nos índices ambientais, e na presença ou não de ventiladores e nebulizadores, nos índices de conforto térmico, utilizando-se três repetições por tratamento. Avaliaram-se os índices de conforto térmico com base na temperatura ambiente (TA), umidade relativa do ar (UR), índice de temperatura do globo negro e umidade (ITGU) e carga térmica de radiação (CTR) obtidos em intervalos regulares de duas horas, das 8 às 16 h, pelo período de dez dias, em cada tratamento.

\section{Caracterização dos aviários}

Todos os galpões estavam orientados no sentido LesteOeste, não possuíam lanternins, tinham piso concretado, laterais protegidas com telas de arame galvanizado, cortinas manuais, cama com $10 \mathrm{~cm}$ de espessura, composta de palha de arroz ou bagaço de cana-de-açúcar; analisaram-se os seguintes tratamentos:

Telha de amianto sem ventilação artificial (TASV): galpões com média de 72,0 $\mathrm{m}$ de comprimento por 11,0 m de largura, pé direito de 3,0 m e beiral de $1,8 \mathrm{~m}$, muretas com $0,30 \mathrm{~m}$, além de comedouros e bebedouros pendulares. A distância entre os galpões era, em média, de $60 \mathrm{~m}$ e densidade de alojamento de 10 aves $\mathrm{m}^{2}$. Neste tratamento prevaleceram as condições climáticas naturais do ambiente.

Telha de barro sem ventilação artificial (TBSV): galpões com média de $60,0 \mathrm{~m}$ de comprimento por $8,0 \mathrm{~m}$ de largura, pé direito de $3,0 \mathrm{~m}$ e beiral de $2,2 \mathrm{~m}$, muretas com $0,40 \mathrm{~m}$, além de comedouros e bebedouros pendulares. A distância entre os galpões era, em média, de $40 \mathrm{~m}$ e densidade de alojamento de 10 aves $\mathrm{m}^{2}$. Neste tratamento prevaleceram as condições climáticas naturais do ambiente.

Telha de cimento amianto com ventilação artificial (TACV): galpões com média de 72,0 $\mathrm{m}$ de comprimento por $11,0 \mathrm{~m}$ de largura, pé direito de 3,0 m e beiral de $1,8 \mathrm{~m}$, muretas com $0,30 \mathrm{~m}$, além de comedouros e bebedouros pendulares. A distância média entre os galpões era de $70 \mathrm{~m}$ e densidade de alojamento de 10 aves $\mathrm{m}^{2}$. O sistema de ventilação se compunha de quatro ventiladores helicoidais, que eram acionados quando a temperatura do ar atingia $25^{\circ} \mathrm{C}$.

Telha de barro com sistema de ventilação artificial (TBCV): galpões com média de 75,0 $\mathrm{m}$ de comprimento por 9,0 $\mathrm{m}$ de largura, pé direito de $2,30 \mathrm{~m}$ e beiral de $0,50 \mathrm{~m}$, muretas com $0,30 \mathrm{~m}$. A distância entre os galpões era em média de $12 \mathrm{~m}$. Os comedouros eram automáticos e pendulares e bebedouros 
pendulares e densidade de alojamento de 10 aves $\mathrm{m}^{2}$. O sistema de ventilação se compunha de três ventiladores helicoidais, que eram acionados quando a temperatura do ar atingia $25^{\circ} \mathrm{C}$.

Telha de cimento amianto com ventilação artificial e nebulização (TAVN): galpões com média de 105,0 m de comprimento por 11,0 m de largura, pé direito de 3,2 $\mathrm{m}$ e beiral de 1,2 m, muretas com $0,22 \mathrm{~m}$, além de comedouros e bebedouros automáticos. A distância entre os galpões era em média de 60 $\mathrm{m}$ e densidade de alojamento de 12 aves $\mathrm{m}^{2}$. A ventilação artificial era composta por dezoito ventiladores posicionados em duas linhas, os quais eram acionados quando a temperatura do ar atingia valores iguais ou superiores a $25^{\circ} \mathrm{C}$. O sistema de nebulização era constituído de duas linhas eqüidistantes, entrando em funcionamento para temperaturas do ar superiores a $29^{\circ} \mathrm{C}$, e desligados quando a umidade relativa do ar alcançava $80 \%$ ou quando se presenciava condensação sobre a cama.

Telha de barro com ventilação artificial e nebulização (TBVN): galpões com média de 105,0 $\mathrm{m}$ de comprimento por $11,0 \mathrm{~m}$ de largura, pé direito de 3,2 m e beiral de 1,2 m; as muretas com $0,22 \mathrm{~m}$, além de comedouros e bebedouros automáticos. A distância entre os galpões era, em média, de $50 \mathrm{~m}$ e densidade de alojamento de 13 aves $\mathrm{m}^{2}$. A ventilação se compunha de dezoito ventiladores posicionados em duas linhas, que eram acionados quando a temperatura do ar atingia $25^{\circ} \mathrm{C}$. O sistema de nebulização constituía-se de duas linhas eqüidistantes do eixo do galpão, entrando em funcionamento para temperaturas do ar acima de $29^{\circ} \mathrm{C}$, e desligados quando a umidade era superior a $80 \%$ ou, então, quando se presenciava condensação sobre a cama.

Telha de cimento amianto com ventilação artificial e aspersão sobre a cobertura (TAVA): galpões com média de $50,0 \mathrm{~m}$ de comprimento por 9,0 m de largura, pé direito de $3,0 \mathrm{~m}$, beiral de 1,8 m e muretas com $0,40 \mathrm{~m}$, além de comedouros automáticos e bebedouros pendulares. A distância entre os galpões era, em média, de $45 \mathrm{~m}$ e densidade de alojamento de 10 aves $\mathrm{m}^{2}$. O sistema de ventilação se compunha de ventiladores que eram acionados quando a temperatura do ar atingia $25^{\circ} \mathrm{C}$. O sistema de aspersão sobre a cobertura era constituído de dois tubos de polietileno, um em cada lateral do telhado, aos quais foram introduzidos os aspersores, que eram acionados quando a temperatura do ar atingia $25^{\circ} \mathrm{C}$.

\section{Instrumentos e medições}

As leituras foram feitas durante dez dias experimentais, a cada duas horas, no intervalo das 8 às $16 \mathrm{~h}$, sendo realizadas as seguintes medições: temperatura de bulbo seco, bulbo úmido, globo negro e velocidade do vento, a $0,35 \mathrm{~m}$ acima do nível da cama, correspondendo ao centro de massa das aves. Com esses dados encontrou-se o valor da tempe-ratura do ambiente e se calcularam os valores da UR, do ITGU e da CTR, nos horários considerados, sendo que estes dois últimos índices foram calculados pelas equações proposta por Buffington et al. (1997) e Esmay (1969), respectivamente. Essas medições foram iniciadas quando as aves tinham idade acima de 30 dias. $\mathrm{O}$ experimento foi montado no delineamento em blocos casualizados (DBC), com sete sistemas de acondicionamento térmico (tratamentos), cinco horários (8, 10, 12, 14 e 16 h) e três repetições. As médias foram comparadas utilizando-se o teste de Tukey, adotando-se o nível de 5\% de significância. Para análise estatística dos resultados utilizou-se o programa SAEG 7.0 (Sistemas de Análises Estatísticas e Genéticas) desenvolvido na Universidade Federal de Viçosa, MG.

\section{RESULTADOS E DISCUSSÃO}

\section{Temperatura ambiente}

Os resultados médios diários da temperatura ambiente encontram-se relacionados na Tabela 1 , na qual se verifica, de maneira geral, diferença significativa $(\mathrm{P}<0,05)$ na temperatura ambiente para os sistemas de acondicionamento, nos horários de observação. Às $8 \mathrm{~h}$, embora com os sistemas de acondicionamento desligados ou iniciando seu funcionamento, ocorreu diferença significativa entre eles e o tratamento TBCV; mesmo não diferindo estatisticamente do tratamento TAVN, apresentou valor superior a $28,0{ }^{\circ} \mathrm{C}$. Tomando-se como base este valor e segundo as recomendações de Baêta \& Souza (1997) e Tinôco (2001), pode-se concluir que as aves estavam fora da zona de conforto térmico.

Tabela 1. Valores médios* da temperatura ambiente interna, em ${ }^{\circ} \mathrm{C}$, para os diferentes horários e sistemas de cobertura analisados

\begin{tabular}{cllllc}
\hline \multirow{2}{*}{ Sistemas } & \multicolumn{5}{c}{ Horários } \\
\cline { 2 - 6 } & \multicolumn{1}{c}{$8: 00$} & $10: 00$ & \multicolumn{1}{c}{$12: 00$} & $14: 00$ & $16: 00$ \\
\hline TASV & $26,13 \mathrm{c}$ & $29,06 \mathrm{ab}$ & $30,87 \mathrm{a}$ & $30,77 \mathrm{a}$ & $28,70 \mathrm{a}$ \\
TBSV & $26,23 \mathrm{bc}$ & $28,63 \mathrm{bc}$ & $30,40 \mathrm{ab}$ & $30,67 \mathrm{a}$ & $29,53 \mathrm{a}$ \\
TACV & $26,36 \mathrm{bc}$ & $29,66 \mathrm{ab}$ & $30,60 \mathrm{a}$ & $30,50 \mathrm{ab}$ & $29,20 \mathrm{a}$ \\
TBCV & $28,96 \mathrm{a}$ & $30,53 \mathrm{a}$ & $31,83 \mathrm{a}$ & $30,90 \mathrm{a}$ & $29,60 \mathrm{a}$ \\
TAVN & $27,97 \mathrm{ab}$ & $30,07 \mathrm{ab}$ & $30,20 \mathrm{ab}$ & $29,41 \mathrm{ab}$ & $27,83 \mathrm{a}$ \\
TBVN & $25,79 \mathrm{c}$ & $27,06 \mathrm{c}$ & $28,69 \mathrm{~b}$ & $28,80 \mathrm{~b}$ & $28,21 \mathrm{a}$ \\
TAVA & $26,40 \mathrm{bc}$ & $28,90 \mathrm{ab}$ & $30,94 \mathrm{a}$ & $30,46 \mathrm{ab}$ & $27,86 \mathrm{a}$ \\
\hline
\end{tabular}

* As médias seguidas de pelo menos uma mesma letra na coluna não diferem a nível de 5\% de probabilidade, pelo teste de Tukey

No horário das $10 \mathrm{~h}$ observa-se que apenas o tratamento TBVN, mesmo não indicando diferença com o sistema TBSV, foi o único que apresentou valor de TA inferior a $28,0{ }^{\circ} \mathrm{C}$, demonstrando a eficiência do sistema de acondicionamento do ambiente. No horário das $12 \mathrm{~h}$, um dos mais quentes, a TBVN, apesar de não diferir estatisticamente da TAVN nem da TBSV, foi a mais eficiente na redução da temperatura, seguida da TAVN, mostrando os efeitos benéficos dos sistemas em que se utiliza a ventilação e a nebulização.

No horário das $14 \mathrm{~h}$ os sistemas TACV, TAVN, TBVN e TAVA não diferiram, mas os sistemas TBVN e TAVN continuaram propiciando uma temperatura mais baixa que os outros sistemas. Nos horários das 12 e 14 h, todos os tratamentos tiveram valores de TA superiores a $28,0{ }^{\circ} \mathrm{C}$ e, portanto, fora das condições ideais de produção. No horário das 16 horas, período em que a temperatura foi menor e não variou dentro dos aviários, independente do sistema de acondicionamento, observou-se que os tratamentos TAVN e TAVA mostraram valores inferiores a $28,0^{\circ} \mathrm{C}$, com o sistema TBVN também muito próximo deste valor. No caso do sistema TBVN, este fato pode ser justificado pela maior densidade de aves criadas neste sistema, com liberação de uma quantidade 
maior de calor para o meio ambiente, propiciando temperatura mais elevada.

Esses elevados valores da temperatura no interior dos aviários foram semelhantes aos encontrados por Hardoin (1989) o qual verificou que a temperatura interna de aviários com e sem lanternins, ultrapassa o valor considerado confortável para as aves, a partir das 9:30 h, ficando o ambiente desconfortável por um período diário superior a 6 h. Nããs et al. (2001) também constataram, em aviários de frangos de corte, no horário das 14:30 h, valores superiores a $28,0{ }^{\circ} \mathrm{C}$. Essas elevadas temperaturas estão de acordo com as descritas por Perdomo (1998) para a região Nordeste, e Furtado et al. (2002) que concluíram que na microrregião de Campina Grande, $\mathrm{PB}$, como nas diversas mesorregiões do Estado da Paraíba, para os períodos diurnos as aves estavam, a partir da terceira semana, em situação de desconforto térmico.

Os menores valores de TA para todos os sistemas de acondicionamento de ambiente ocorreram pela manhã, crescendo gradualmente até o valor máximo, entre 12 e 14 h, e decrescendo até o final do dia, em razão da diminuição da umidade relativa do ar e do aumento da carga térmica de radiação. Com base na TA, o sistema TBVN apresentou as menores temperaturas, seguido do TAVN. Os sistemas TASV, TACV e TAVA foram semelhantes, em termos de TA, e o sistema TBCV mostrou as temperaturas mais elevadas. No caso da alta temperatura no sistema TBCV, a justificativa para tal fato é que as medições realizadas neste tipo de galpão ocorreram apenas na microrregião de Guarabira, já que era onde se localizavam os galpões, com pequena distância entre eles, telhas já bastante enegrecidas pelo tempo, pé-direito muito baixo $(2,30 \mathrm{~m})$ e um beiral reduzido $(0,5 \mathrm{~m})$, fatos que contribuíram para que este índice fosse o mais elevado.

\section{Umidade relativa do ar (UR)}

Os resultados médios diários internos da umidade relativa do ar encontram-se relacionados na Tabela 2, na qual se verifica diferença significativa $(P<0,05)$ na umidade relativa do ar, entre os sistemas de acondicionamento ambiental nos diferentes horários de observação. Às 8 h, os sistemas de acondicionamento apresentaram diferença significativa, mesmo com os sistemas desligados ou entrando em funcionamento, sobretudo aqueles com nebulizadores, sendo que o sistema TBVN indicou umidade mais elevada, mostrando que a influência desse sistema de acondicionamento se estende durante o período noturno, refletindo nos valores de UR, nas primeiras horas. Observa-se, também, que o sistema foi, neste horário, o único a ter uma UR considerada acima da zona de conforto térmico que, segundo as recomendações, deve ficar entre 50 e $70 \%$ (Baêta \& Souza, 1997 e Tinôco, 2001). No horário das 10 horas o sistema TBVN manteve uma umidade mais elevada, diferindo estatisticamente das demais mas ainda acima da recomendada pelos autores mencionados, embora já dentro das recomendações máximas citadas por Moura (2001). No horário das 12, 14 e 16 horas, os sistemas em que se utilizaram sistemas adiabáticos evaporativos (TAVN e TBVN) mantiveram uma umidade mais elevada, mostrando a eficiência dos sistemas de resfriamento evaporativo.
Tabela 2. Valores médios* da umidade relativa do ar interna, em $\%$, para os diferentes horários e sistemas de cobertura analisados

\begin{tabular}{cccccc}
\hline \multirow{2}{*}{ Sistemas } & \multicolumn{5}{c}{ Horários } \\
\cline { 2 - 6 } & $8: 00$ & $10: 00$ & $12: 00$ & $14: 00$ & $16: 00$ \\
\hline TASV & $71,94 \mathrm{bc}$ & $59,50 \mathrm{~b}$ & $53,63 \mathrm{bc}$ & $52,10 \mathrm{c}$ & $59,07 \mathrm{bc}$ \\
TBSV & $62,95 \mathrm{c}$ & $61,19 \mathrm{~b}$ & $54,58 \mathrm{bc}$ & $52.45 \mathrm{c}$ & $55,37 \mathrm{bc}$ \\
TACV & $75,60 \mathrm{ab}$ & $62,27 \mathrm{~b}$ & $56,68 \mathrm{bc}$ & $55.57 \mathrm{bc}$ & $59,75 \mathrm{bc}$ \\
TBCV & $69,36 \mathrm{bc}$ & $62,47 \mathrm{~b}$ & $57,58 \mathrm{bc}$ & $57,80 \mathrm{bc}$ & $61,40 \mathrm{abc}$ \\
TAVN & $70,49 \mathrm{bc}$ & $61,57 \mathrm{~b}$ & $60,67 \mathrm{ab}$ & $63,38 \mathrm{ab}$ & $69,30 \mathrm{ab}$ \\
TBVN & $84,02 \mathrm{a}$ & $79,10 \mathrm{a}$ & $67,96 \mathrm{a}$ & $68,50 \mathrm{a}$ & $71,37 \mathrm{a}$ \\
TAVA & $64,79 \mathrm{c}$ & $55,35 \mathrm{~b}$ & $47,87 \mathrm{c}$ & $49,44 \mathrm{c}$ & $57,96 \mathrm{bc}$ \\
\hline
\end{tabular}

* As médias seguidas de pelo menos uma mesma letra na coluna não diferem a nível de $5 \%$ de probabilidade, pelo teste de Tukey

Observa-se que, em todas as situações, a umidade relativa do ar média dentro dos aviários esteve, na maioria dos horários pesquisados, de acordo com o recomendado, apresentando, nos horários da 12 e $14 \mathrm{~h}$ no sistema TAVA, valor inferior a $50 \%$ e o sistema TBVN mostrou valor superior a 70\% nos horários de 8 e 10 hs.

Verifica-se, em todos os sistemas, que os valores de UR foram decrescentes até as 12 e $14 \mathrm{~h}$ aproximadamente, crescendo a partir deste horário, conforme esperado, seguindo uma curva com concavidade inversa ao ITGU. Esta tendência também foi verificada por Tinôco (1996), Moraes et al. (1999), Zanolla et al. (1999) e Matos (2001). Com base na UR, principalmente nos horários mais quentes do dia, os sistemas TBVN e TAVN apresentaram os maiores valores, seguidos dos sistemas TBCV, TACV, TBSV, TASV e TAVA. Esta maior umidade relativa do ar nos sistemas TBVN e TAVN pode ser justificada pela presença dos nebulizadores, que injetam certa quantidade de água no ambiente, em forma de vapor, elevando a umidade relativa do ar.

\section{Índice de temperatura de globo negro e umidade (ITGU)}

Os resultados médios diários internos do índice de temperatura do globo negro e umidade encontram-se relacionados na Tabela 3, na qual se verifica, de maneira geral, diferença significativa $(P<0,05)$ no ITGU para os sistemas de acondicionamento ambiental, nos diferentes horários de observação.

Observa-se também, no horário das $8 \mathrm{~h}$, que os sistemas de acondicionamento apresentaram diferença significativa, mesmo com os sistemas desligados ou entrando em funcionamento,

Tabela 3. Valores médios* do índice de temperatura de globo negro e umidade interna, para os diferentes horários e sistemas de cobertura analisados

\begin{tabular}{llllll}
\hline \multirow{2}{*}{ Sistemas } & \multicolumn{5}{c}{ Horários } \\
\cline { 2 - 6 } & \multicolumn{1}{c}{$8: 00$} & \multicolumn{1}{c}{$10: 00$} & $12: 00$ & $14: 00$ & \multicolumn{1}{c}{$16: 00$} \\
\hline TASV & $76,57 \mathrm{bc}$ & $79,33 \mathrm{bc}$ & $81,16 \mathrm{ab}$ & $80,61 \mathrm{a}$ & $78,08 \mathrm{abc}$ \\
TBSV & $77,95 \mathrm{abc}$ & $79,27 \mathrm{bc}$ & $80,97 \mathrm{ab}$ & $80,72 \mathrm{a}$ & $79,73 \mathrm{abc}$ \\
TACV & $78,11 \mathrm{abc}$ & $80,01 \mathrm{abc}$ & $82,11 \mathrm{ab}$ & $80,95 \mathrm{a}$ & $79,41 \mathrm{abc}$ \\
TBCV & $79,93 \mathrm{a}$ & $82,14 \mathrm{a}$ & $82,84 \mathrm{a}$ & $80,92 \mathrm{a}$ & $80,01 \mathrm{ab}$ \\
TAVN & $79,28 \mathrm{ab}$ & $81,02 \mathrm{ab}$ & $80,40 \mathrm{ab}$ & $79,83 \mathrm{a}$ & $80,56 \mathrm{a}$ \\
TBVN & $76,78 \mathrm{bc}$ & $78,54 \mathrm{c}$ & $79,34 \mathrm{~b}$ & $78,36 \mathrm{a}$ & $77,38 \mathrm{bc}$ \\
TAVA & $76,00 \mathrm{c}$ & $78,90 \mathrm{bc}$ & $80,80 \mathrm{ab}$ & $80,00 \mathrm{a}$ & $77,08 \mathrm{c}$ \\
\hline
\end{tabular}

* As médias seguidas de pelo menos uma mesma letra na coluna não diferem a nível de $5 \%$ de probabilidade, pelo teste de Tukey 
sendo que os sistemas TBCV e TAVN indicaram valores mais elevados para o ITGU. No horário das $10 \mathrm{~h}$ constatou-se que os sistemas TBCV e TAVN continuaram mostrando valores elevados de ITGU e, no horário das 12 e $14 \mathrm{~h}$, houve pequenas variações estatísticas, com os valores de ITGU os mais elevados registrados, demonstrando que nos horários mais quentes do dia os sistemas de acondicionamento térmico utilizados não foram suficientes para reduzir este índice.

Considerando-se que o ITGU com valor de até 77 não influencia no desempenho das aves (Teixeira, 1983) vê-se que apenas o tratamento TASV apresentou, no horário das $8 \mathrm{~h}$, valor dentro do recomendado, embora diferindo apenas dos tratamentos TACV e TBVN. Esses dados demonstram a necessidade de se melhorar os sistemas de acondicionamento utilizados, já que estes se mostraram ineficientes na diminuição do ITGU. Outro aspecto a se considerar é que, em condições de campo, uma significativa parcela de sobreaquecimento advém do próprio calor gerado pelas aves, agravando mais a situação de desconforto térmico no interior das instalações.

Altos valores de ITGU também foram verificados nos trabalhos realizados por Hardoin (1989) em aviários com e sem lanternins, onde o autor verificou que as aves estiveram expostas ao ambiente termicamente desconfortável a partir das $8 \mathrm{~h} 11 \mathrm{~min}$, por um período superior a $7 \mathrm{~h}$. Lopes (1999) em pesquisa realizada com matrizes de frangos de corte na região do Triângulo Mineiro, no período matinal, obteve valores de ITGU oscilando em torno de 80. Nããs et al. (2001) em experimentos realizados com modelos em escala reduzida encontraram, no horário das $14 \mathrm{~h}$, valores de ITGU também superiores aos recomendados.

Os valores de ITGU atingiram o máximo entre as 12 e $14 \mathrm{~h}$ (período mais quente do dia), devido à elevação das temperaturas das vizinhanças do globo negro, principalmente das temperaturas do solo aquecido e da superfície inferior da cobertura, que são mais elevadas quando a irradiância solar global também é elevada (Rosa, 1984). O aumento da temperatura das secções da vizinhança do globo faz com que ele receba mais calor do ambiente, acarretando elevação da sua temperatura com conseqüente elevação nos valores de ITGU.

Observa-se que os valores médios de ITGU aumentaram a partir das $10 \mathrm{~h}$, atingindo um máximo entre 12 e $14 \mathrm{~h}$, decrescendo em seguida, até as $16 \mathrm{~h}$. Este comportamento diurno dos valores de ITGU também foi verificado por Piasentin (1984), Rosa (1984), Campos (1986), Tinôco (1996), Fonseca (1998), Zanolla et al. (1999), Moraes et al. (1999) e Matos (2001).

Por sua vez, o ITGU mostra, nos sete sistemas de acondicionamento do ambiente, diferença mais acentuada no horário das $12 \mathrm{~h}$ e, também, que os sistemas TBVN, TAVA, TACV e TBSV apresentaram menores valores de ITGU, sobretudo nos horários mais quentes do dia, e os mais elevados no TBCV. Além disso, no sistema TAVN não ocorreu diferença significativa entre os horários, demonstrando que o ITGU se manteve constante ao longo do dia, com o sistema funcionando perfeitamente. No caso específico do sistema TBCV, o ITGU seguiu a tendência da temperatura ambiente, pelos motivos já citados.

\section{Carga térmica de radiação (CTR)}

Os resultados médios diários internos da carga térmica de radiação encontram-se relacionados na Tabela 4, na qual se verifica, de maneira geral, diferença significativa $(\mathrm{P}<0,05)$ na CTR, entre os sistemas de acondicionamento ambiental, nos diferentes horários de observação. Vê-se que, no horário das 8 $\mathrm{h}$, quando os sistemas estavam desligados ou entrando em funcionamento, ocorreu diferença significativa entre eles e que o sistema TBCV apresentou os valores mais elevados, demonstrando a influência das instalações utilizadas. Nos outros horários constatam-se variações estatísticas entre eles, em que os sistemas TBCV e TACV apresentaram valores mais elevados de CTR nos horários das 10 e entre 12 e 14 h, respectivamente.

Tabela 4. Valores médios* da carga de radiação interna, em W m${ }^{2}$, para os diferentes horários e sistemas de cobertura analisados

\begin{tabular}{cccccc}
\hline \multirow{2}{*}{ Sistemas } & \multicolumn{5}{c}{ Horários } \\
\cline { 2 - 6 } & \multicolumn{1}{c}{$8: 00$} & $10: 00$ & $12: 00$ & $14: 00$ & $16: 00$ \\
\hline TASV & $479,66 \mathrm{~b}$ & $497,82 \mathrm{~b}$ & $509,46 \mathrm{bc}$ & $505,31 \mathrm{ab}$ & $485,23 \mathrm{ab}$ \\
TBSV & $487,65 \mathrm{ab}$ & $500,17 \mathrm{~b}$ & $512,62 \mathrm{bc}$ & $508,71 \mathrm{a}$ & $504,35 \mathrm{a}$ \\
TACV & $506,04 \mathrm{a}$ & $506,79 \mathrm{~b}$ & $542,05 \mathrm{a}$ & $525,20 \mathrm{a}$ & $510,04 \mathrm{a}$ \\
TBCV & $508,03 \mathrm{a}$ & $533,30 \mathrm{a}$ & $529,86 \mathrm{ab}$ & $508,98 \mathrm{a}$ & $509,58 \mathrm{a}$ \\
TAVN & $498,26 \mathrm{ab} 3,94 \mathrm{ab}$ & $501,88 \mathrm{c}$ & $501,64 \mathrm{ab}$ & $492,07 \mathrm{a}$ \\
TBVN & $496,68 \mathrm{ab}$ & $489,04 \mathrm{~b}$ & $501,31 \mathrm{c}$ & $480,20 \mathrm{~b}$ & $464,60 \mathrm{~b}$ \\
TAVA & $479,69 \mathrm{~b}$ & $503,60 \mathrm{~b}$ & $517,30 \mathrm{bc}$ & $508,76 \mathrm{a}$ & $485,89 \mathrm{ab}$
\end{tabular}

* As médias seguidas de pelo menos uma mesma letra na coluna não diferem a nível de $5 \%$ de probabilidade, pelo teste de Tukey

Considerando-se como referência os valores de CTR $=498,3$ $\mathrm{W} \mathrm{m}^{-2}$, indicados por Rosa (1984) para o sistema com telha de barro, observa-se que os valores encontrados nos tratamentos com este tipo de telha, foram inferiores apenas no horário das $8 \mathrm{~h}$, no sistema TBSV, e nos horários das $8,10,14$ e $16 \mathrm{~h}$, no sistema TBVN. Quanto aos abrigos em que se utilizaram telhas de cimento amianto (CTR $=515,4 \mathrm{~W} \mathrm{~m}^{-2}$ ), observa-se que nos horários das 8,10 e $16 \mathrm{~h}$ todos os tratamentos tiveram valores inferiores e, no horário das $12 \mathrm{~h}$, os tratamentos TACN e TAVA apresentaram valor superior a este. No horário das $14 \mathrm{~h}$, apenas o tratamento TACV mostrou valor superior ao de referência.

Em todos os tratamentos, com exceção do TAVN, os menores e maiores valores de CTR ocorreram às $8 \mathrm{e}$ às $16 \mathrm{~h}$ e às $12 \mathrm{e} 14$ $\mathrm{h}$, respectivamente. Este comportamento diurno da CTR também foi verificado por Piasentin (1984), Rosa (1984), Campos (1986), Tinôco (1996), Fonseca (1998), Zanolla et al. (1999), Nããs et al. (2001) e Matos (2001); isto pode ser explicado pelo fato de que os valores que definem a CTR ocorrem em função principalmente da irradiação solar direta, a qual atinge os valores mais elevados próximos de $12 \mathrm{~h}$, quando o sol se posiciona de forma mais perpendicular ao plano do horizonte local e, também, em função da radiação de ondas longas emitidas pela vizinhança (Fonseca, 1998).

O sistema TBVN foi o que apresentou os menores valores de CTR, seguido do TAVN, enquanto os sistemas TACV e TBCV apresentaram maiores valores de carga térmica radiante. No caso específico dos sistemas TBVN e TAVN, a CTR seguiu a tendência da temperatura ambiente e do ITGU, já que a CTR é influenciada por esses dois índices, baseando-se nas conclusões feitas anteriormente. 


\section{CONCLUSÕES}

Nas condições de realização do experimento, conclui-se que:

1. Há forte influência da tipologia nas condições ambientais no interior dos galpões, devendo-se observar as normas técnicas para se obter um bom acondicionamento térmico

2. A temperatura do ar, o índice de temperatura de globo negro e umidade e a carga térmica de radiação apresentaram, nos horários mais quentes, valores médios considerados acima do ideal para frangos de corte. Os valores da umidade relativa do ar permaneceram dentro da faixa considerada ideal.

3. O sistema com telha de barro, ventilação artificial e nebulização apresentou, na região do Agreste Paraibano, os melhores valores de acondicionamento térmico para aves de corte.

\section{LITERATURA CITADA}

ABEF - Associação Brasileira de Exportadores de Frangos de corte. Disponível em http://www.abef .com.br. Consulta em março de 2003.

Baêta, F.C.; Souza, C.F. Ambiência em edificações rurais conforto animal, Viçosa, MG: UFV, 1997, 246p.

Brasil. Ministério da Agricultura: Levantamento exploratório reconhecimento de solos do Estado da Paraíba. II Interpretação para uso agrícola dos solos do Estado da Paraíba. M.A./CONTAP/USAID/BRASIL. Rio de Janeiro. 1972. 683p. Boletim DPFS. EPE-MA, 15 - Pedologia, 8

Buffington, C.S.; Collazo-Arodio, A.; Canton, G.H.; Pitt, D.; Thatcher, W.W.; Colier, R.J. Black globe humidity comfort index for dairy cows. St. Joseph: ASAE, 1997. 19p. Paper 774517

Campos, A.T. Determinação dos índices de conforto térmico e da carga térmica de radiação em quatro tipos de galpões em condições de verão para Viçosa, MG. Viçosa: UFV, 1986, 66p. Dissertação Mestrado

Esmay, M.L. Principles of animal environment. 2. ed. Westport CJ, AGI Publishing Co., 1969, 325p.

Fonseca, J.M. Efeito da densidade de alojamento sobre o desempenho de frangos de corte criados em sistemas de nebulização e ventilação em túnel. Viçosa: UFV, 1998. 57p. Dissertação Mestrado

Furtado, D.A.; Azevedo, P.V.; Santos Jr., R.L.; Assis, P.C.O. Parâmetros de conforto térmico para produção animal nas mesorregiões do Estado da Paraíba. In. Congresso Brasileiro de Meteorologia, 13, Foz de Iguaçu. Anais... Foz de Iguaçu: SBMET, 2002. CD-Rom

Hardoin, P.C. Estudo do lanternim em instalações avícolas. Viçosa: UFV, 1989. 69p. Dissertação Mestrado

Lopes, S.P. Efeitos de densidade, programas e fontes de luz, durante a fase de recria, sobre o desempenho de matrizes de frangos de corte. Belo Horizonte: UFMG, 1999. 75p. Tese Doutorado
Matos, M.L. Conforto térmico ambiente e desempenho de frangos de corte, alojados em dois níveis de alta densidade, em galpões com sistemas de ventilação em túnel e ventilação lateral. Viçosa: UFV, 2001. 89p. Dissertação Mestrado

Moraes, S.R.P.; Tinôco, I.F.F.; Baêta, F.C.; Cecon, P.C. Conforto térmico em galpões avícolas, sob coberturas de cimento amianto e suas diferentes associações. Revista Brasileira de Engenharia Agrícola e Ambiental, Campina Grande, v.3, n.1, p.89-92, 1999.

Moura, D.J. Ambiência na avicultura de corte. In: Silva, I.J.O. Ambiência na produção de aves em clima tropical. Piracicaba: FUNEP, 2001. p.75-149.

Nããs, I.A.; Sevegnani, K.B.; Marcheto, F.G.; Espelho, J.C.C.; Menegassi, V.; Silva, I.J.O. Avaliação térmica de telhas de composição de celulose e betumem, pintadas de branco, em modelos de aviários com escala reduzida. Engenharia Agrícola, Jaboticabal, v.21, n.2, p.121-126, 2001.

Perdomo, C.C. Mecanismos de aclimatização de frangos de corte como forma de reduzir a mortalidade no inverno e verão. In: Simpósio Internacional sobre Instalações e Ambiência, 1998, Campinas. Anais... Campinas. p.229-240, 1998.

Piasentin, J.A. Conforto medido pelo índice de temperatura do globo e umidade na produção de frangos de corte para dois tipos de pisos em Viçosa, MG. Viçosa: UFV, 1984. 77p. Dissertação Mestrado

Rosa, Y.B.C.J. Influência de três materiais de cobertura no índice de conforto térmico em condições de verão, para Viçosa MG. Viçosa: UFV, 1984. 77p. Dissertação Mestrado

Silva, I.J.O.; Sevegnani, K.B. Ambiência na produção de aves de postura. In: Silva, I. J. O. Ambiência na produção de aves em clima tropical. Piracicaba: FUNEP, 2001. p.150-214.

Teixeira, V.H. Estudo dos índices de conforto em duas instalações de frango de corte para as regiões de Viçosa e Visconde do Rio Branco, MG. Viçosa: UFV, 1983, 59p. Dissertação Mestrado

Tinôco, I.F.F. Efeito de diferentes sistemas de acondicionamento de ambiente e níveis de energia metabolizável na dieta sobre o desempenho de matrizes de frangos de corte, e condições de verão e outono. Belo Horizonte: UFMG, 1996. 169p. Tese Doutorado

Tinôco, I.F.F. Ambiência e instalações para a avicultura industrial. In: Congresso Brasileiro de Engenharia Agrícola, 27, e Encontro Nacional de Técnicos, Pesquisadores e Educadores de Construções Rurais, 3, 1998, Poços de Caldas, MG. Anais... Lavras: UFLA/SBEA, 1998, p.1-86.

Tinôco, I.F.F. Avicultura industrial: novos conceitos de materiais, concepções e técnicas construtivas disponíveis para galpões avícolas brasileiros. Revista Brasileira de Ciência Avícola, Campinas. v.3, n.1, p.1-26, 2001.

Zanolla, N.; Tinôco, I.F.F.; Baêta, F.C.; Cecon, P.R.; Moraes, S.R.P. Sistemas de ventilação em túnel e lateral na criação de frangos de corte em alta densidade. Revista Brasileira de Engenharia Agrícola e Ambiental, Campina Grande, v.3, n.3, p.361-366, 1999 . 